\title{
Differential Expression of Apoptotic Protease-Activating Factor-1 and Caspase-3 Genes and Susceptibility to Apoptosis during Brain Development and after Traumatic Brain Injury
}

\author{
Alexander G. Yakovlev, ${ }^{1}$ Katsuya Ota, ${ }^{2}$ Geping Wang, ${ }^{1}$ Vilen Movsesyan,, Wei-Li Bao, ${ }^{1}$ Koichiro ${ }^{1}$ Yoshihara, ${ }^{2}$ \\ and Alan I. Faden ${ }^{1}$ \\ 1Department of Neuroscience, Georgetown University, Washington, DC 20007, and 2Department of Biochemistry, Nara \\ Medical University, Kashihara, Nara 634-8521, Japan
}

Neuronal apoptosis plays an essential role in early brain development and contributes to secondary neuronal loss after acute brain injury. Recent studies have provided evidence that neuronal susceptibility to apoptosis induced by traumatic or ischemic injury decreases during brain development. However, the molecular mechanisms responsible for this age-dependent phenomenon remain unclear. Here we demonstrate that, during brain maturation, the potential of the intrinsic apoptotic pathway is progressively reduced and that such repression is associated with downregulation of apoptotic protease-activating factor-1 (Apaf-1) and caspase-3 gene expression. A similar decline in apoptotic susceptibility associated with downregu- lation of Apaf- 1 expression as a function of developmental age was also found in cultured primary rat cortical neurons. Injuryinduced cytochrome $c$-specific cleavage of caspase- 9 followed by activation of caspase-3 in mature brain correlated with marked increases in Apaf-1 and caspase-3 mRNA and protein expression. These results suggest that differential expression of Apaf-1 and caspase-3 genes may underlie regulation of apoptotic susceptibility during brain development, as well as after acute injury to mature brain, through the intrinsic pathway of caspase activation.

Key words: brain; development; injury; apoptosis; caspase; gene expression; Apaf-1
Apoptosis is a genetically controlled cell death that was initially recognized for its role in development. Nearly half of neural cells die by apoptosis during brain development. However, apoptosis is atypical for mature mammalian brain under normal physiological conditions (Haydar et al., 1999). Recent studies have established a role for apoptosis in neuronal loss after stroke and spinal cord or traumatic brain injury (TBI) (Gillardon et al., 1997; Yakovlev et al., 1997; Lipton, 1999; Snider et al., 1999; Beattie et al., 2000; Clark et al., 2000; Eldadah and Faden, 2000; Raghupathi et al., 2000; Yamashima, 2000). Furthermore, clinical data suggest that outcomes and mortality after acute brain injury are agedependent, with more severe responses in infants than in adults (Brink et al., 1970; Levin et al., 1982; Adelson and Kochanek, 1998). Such differences in response to injury may be explained, in part, by differential susceptibility to apoptosis and associated caspase-3 activity in brain as a function of developmental age (Bittigau et al., 1999; Pohl et al., 1999; Hu et al., 2000). However, the molecular mechanisms underlying such age-dependent differences in apoptotic response to neuronal injury have not been identified.

Because caspase-3 appears to be the major executioner caspase involved in neuronal apoptosis (Bredesen, 2000; Eldadah and

\footnotetext{
Received April 9, 2001; revised July 12, 2001; accepted July 13, 2001.

This work was supported by Grants R01 NS38941 and R01 NS36537 from the National Institute for Neurological Diseases and Stroke to A.G.Y. and A.I.F. and by Grant DAMD17-99-2-9007 from the United States Department of Defense to A.I.F. We thank Dr. Vishva M. Dixit for the dominant negative caspase- 8 and caspase- 9 expression constructs. We also thank Dr. Gabriel Nunez for the cDNA clone encoding human Apaf-1XL.

Correspondence should be addressed to Alexander G. Yakovlev, Georgetown University Medical Center, Research Building, WP-14, 3970 Reservoir Road Northwest, Washington, DC 20007. E-mail: yakovlev@giccs.georgetown.edu. Copyright (ㄷ) 2001 Society for Neuroscience $\quad 0270-6474 / 01 / 217439-08 \$ 15.00 / 0$
}

Faden, 2000), we hypothesized that suppression of apoptotic capability during maturation of mammalian brain results from repression of genes involved in the caspase- 3 activation pathway, and that injury-induced neuronal apoptosis in the mature brain results from reactivation of these genes.

Two major caspase-3-activating pathways have been identified, an extrinsic pathway involving cell surface receptors and an intrinsic pathway resulting from alterations at the level of the mitochondrion and activation of the apoptosome (Li et al., 1997; Scaffidi et al., 1998; Slee et al., 1999). A role for the extrinsic pathway in injury-induced CNS apoptosis remains to be established, whereas a role for the intrinsic pathway is supported by several recent studies (Krajewski et al., 1999; Springer et al., 1999; Kuida, 2000).

The intrinsic pathway is initiated by release of cytochrome $c$ from mitochondria to the cytosol (Li et al., 1997; Zou et al., 1997, 1999; Brown and Borutaite, 1999; Richter and Ghafourifar, 1999; Kulms and Schwarz, 2000; Robertson and Orrenius, 2000). In the presence of ATP (or dATP), cytochrome $c$ binds to the cytosolic adaptor protein apoptotic protease-activating factor-1 (Apaf-1) (Li et al., 1997). Binding of cytochrome $c$ to Apaf-1 allows the recruitment and activation of caspase-9 within the apoptosome (Li et al., 1997). Active caspase-9, in turn, activates executioner caspases-3 and -7 . Activated caspase- 3 is required for the activation of four other caspases $(-2,-6,-8$, and -10$)$ in this pathway and also participates in a feedback amplification loop involving caspase-9 (Li et al., 1997; Slee et al., 1999).

In the present study, we evaluated the role of the intrinsic pathway in neuronal apoptosis at different stages of rat brain development and during maturation of primary cortical neurons in vivo as well as in response to brain injury. 


\section{MATERIALS AND METHODS}

Tissue cultures. Cortical neuronal cultures were derived from rat embryonic cortices. Briefly, cortices from 15- to 16-d-old embryos were cleaned from their meninges and blood vessels in Krebs'-Ringer's bicarbonate buffer containing $0.3 \%$ bovine serum albumin (BSA; Life Technologies, Gaithersburg, MD). Cortices were then minced and dissociated in the same buffer with $1800 \mathrm{U} / \mathrm{ml}$ trypsin (Sigma, St. Louis, MO) at $37^{\circ} \mathrm{C}$ for $20 \mathrm{~min}$. After the addition of $200 \mathrm{U} / \mathrm{ml}$ DNase I (Sigma) and $3600 \mathrm{U} / \mathrm{ml}$ soybean trypsin inhibitor (Sigma) to the suspension, cells were triturated through a $5 \mathrm{ml}$ pipette. After the tissue was allowed to settle for 5-10 min, the supernatant was collected, and the remaining tissue pellet was retriturated. The combined supernatants were then centrifuged through a 4\% BSA layer and the cell pellet was resuspended in neuronal seeding medium, which consisted of neurobasal medium (Life Technologies) supplemented with $1.1 \% 100 \times$ antibiotic-antimycotic solution (Biofluids, Rockville, MD), $25 \mu \mathrm{M}$ Na-glutamate, $0.5 \mathrm{~mm}$ L-glutamine, and 2\% B27 supplement (Life Technologies). Cells were seeded at a density of $5 \times$ $10^{5}$ cells $/ \mathrm{ml}$ onto poly-D-lysine $(70-150 \mathrm{kDa}$; Sigma)-coated 96-well plates (Corning, Corning, NY) or $60 \mathrm{~mm}$ Petri dishes (Falcon). All experiments were performed on cultures at 1 or $14 \mathrm{~d}$ in vitro (DIV). Cell death was induced in cultured neurons by incubation with $50 \mu \mathrm{M}$ etoposide.

The composition of 1 and 14 DIV cortical neuronal cultures was characterized by immunostaining using the mouse monoclonal antineuron-specific enolase (NSE) antibodies. Briefly cultures in 96-well plates were fixed with $4 \%$ paraformaldehyde in PBS and washed twice (5 min each) with PBS. Nonspecific binding was blocked by incubation with $10 \%$ goat serum at $+4^{\circ} \mathrm{C}$ for $16 \mathrm{hr}$. The primary anti-NSE antibodeis (Chemicon, Temecula, CA) in PBS buffer (1:10) were applied for $16 \mathrm{hr}$ at $+4^{\circ} \mathrm{C}$. Cultures were then washed three times ( 5 min each) with PBS and incubated with the secondary antibodies (1:100 dilution; goat antimouse antibodies conjugated to Texas Red; Accurate Chemicals, Westbury, NY) for $45 \mathrm{~min}$. Cultures were washed three times (5 min each) again and examined using phase-contrast (to visualize all types of cells) and UV microscopy (to identify NSE-positive cells). Cells were counted in randomly selected fields in 1 and 14 DIV cultures. No significant differences were found $(n=5 ; p=0.475)$ in the percentages of neuronal cells in 1 and 14 DIV cultures, as compared by ANOVA followed by the Student-Newman-Keuls test. One DIV cultures contained $88 \pm 4 \%$ NSE-positive cells, and 14 DIV cultures contained $91 \pm 5 \%$ NSEpositive cells.

Rat fluid percussion brain trauma model. This model is highly reproducible and has been extensively characterized with regard to its biochemical, physiological, morphological, and behavioral correlates (McIntosh et al., 1987; Faden et al., 1989). Briefly, male Sprague Dawley rats (400 \pm 25 gm body weight) were anesthetized with sodium pentobarbital (60 mg/kg, i.p.), intubated, and implanted with femoral venous and arterial catheters. Brain temperature was assessed indirectly through a thermister in the temporalis muscle, and body temperature was maintained through a feedback-controlled heating blanket. Blood pressure was continuously monitored, and arterial blood gases were analyzed periodically. A small craniotomy $(2 \mathrm{~mm})$, located midway between the lambda and bregma sutures over the left parietal cortex, allowed insertion of a Leur-Loc that was cemented in place. The fluid percussion head injury device, manufactured by the Medical College of Virginia, consists of a Plexiglas cylindrical reservoir filled with $37^{\circ} \mathrm{C}$ isotonic saline; one end includes a transducer that is mounted and connected to a $5 \mathrm{~mm}$ tube that attaches through a male Leur-Loc fitting to the female Leur-Loc cemented at the time of surgery. A pendulum strikes a piston at the opposite end of the device, producing a pressure pulse of $\sim 22 \mathrm{msec}$ duration, leading to the deformation of underlying brain. The degree of injury is related to the pressure pulse expressed in atmospheres; a pulse of $2.4 \pm 0.1$ atmospheres produces moderately severe injury that permits evaluation of pharmacological interventions. Animals were maintained on anesthetics (sodium pentobarbital, $15 \mathrm{mg} \cdot \mathrm{kg}^{-1} \cdot \mathrm{hr}^{-1}$ ) and artificially ventilated. All animal experiments were in compliance with Georgetown University Animal Care and Use Committee guidelines and the National Institutes of Health Guide for the Care and Use of Laboratory Animals (National Institutes of Health publication 85-23).

Assay for caspase-3 activation. Sham-operated and injured rat cortices or pellets of primary cortical neurons were homogenized in a Dounce homogenizer in $20 \mathrm{~mm}$ HEPES-KOH, pH 7.5, $10 \mathrm{~mm} \mathrm{KCl}, 1.5 \mathrm{~mm}$ $\mathrm{MgCl}_{2}, 1 \mathrm{~mm}$ EDTA, $1 \mathrm{~mm}$ EGTA, $1 \mathrm{~mm}$ dithiothreitol (DTT), $1 \mathrm{~mm}$ phenylmethylsulfonyl fluoride (PMSF), $10 \mu \mathrm{g} / \mathrm{ml}$ leupeptin, $10 \mu \mathrm{g} / \mathrm{ml}$ aprotinin, $10 \mu \mathrm{g} / \mathrm{ml}$ pepstatin $\mathrm{A}$, and $250 \mathrm{~mm}$ sucrose. Homogenates were centrifuged at $13,000 \times g$ for $30 \mathrm{~min}$. Supernatants were transferred to new tubes and stored at $-80^{\circ} \mathrm{C}$ until used. Protein concentration was estimated by the Bradford method (Bio-Rad, Hercules, CA) according to recommendations by the manufacturer. Twenty to $80 \mu \mathrm{g}$ aliquots of the cytosolic extracts were incubated in the presence or absence of $1 \mathrm{~mm}$ dATP and $10 \mu \mathrm{g} / \mathrm{ml}$ cytochrome $c$ at $37^{\circ} \mathrm{C}$ for $1 \mathrm{hr}$ in a final volume of 20 $\mu l$ of caspase activation buffer (10 mM HEPES, $\mathrm{pH} 7.4,5$ mM EGTA, 2 mм $\mathrm{MgCl}_{2}$, 5 mм DTT, 1 mм ATP, 1 mм PMSF, $10 \mu \mathrm{g} / \mathrm{ml}$ leupeptin, 10 $\mu \mathrm{g} / \mathrm{ml}$ aprotinin, $10 \mu \mathrm{g} / \mathrm{ml}$ pepstatin A, $10 \mathrm{~mm}$ phosphocreatinin, and 150 $\mu \mathrm{g} / \mathrm{ml}$ creatine kinase). At the end of the incubation, aliquots of reaction mixtures $(20 \mu \mathrm{g}$ of protein in $100 \mu \mathrm{l}$ of caspase-3 assay buffer consisting of $50 \mathrm{~mm}$ HEPES, pH 7.4, $100 \mathrm{~mm} \mathrm{NaCl}, 0.1 \%$ 3-[(3-cholamidopropyl)dimethylammonio]-1-propanesulfonic acid, $10 \mathrm{~mm}$ DTT, $1 \mathrm{~mm}$ EDTA, and $10 \%$ glycerol) were mixed with equal volumes of $40 \mu \mathrm{M}$ fluorescent tetrapeptide substrate [Ac-DEVD-aminomethylcoumarin (AMC); Bachem] in the same buffer solution. Caspase-3-like activity was measured using a CytoFluor 4000 fluorometer (PerSeptive Biosystems) as described below.

Assay for caspase activity. Aliquots of cytosolic extracts $(20 \mu \mathrm{g}$ of protein in $100 \mu \mathrm{l}$ of caspase-3 assay buffer) were mixed with equal volumes of $40 \mu \mathrm{M}$ Ac-DEVD-AMC in the same buffer. Free AMC accumulation, which resulted from cleavage of the aspartate-AMC bond, was monitored continuously in each sample over $30 \mathrm{~min}$ in 96-well microtiter plates using a CytoFluor 4000 fluorometer at $360 \mathrm{~nm}$ excitation and 460 emission wavelengths. The emission from each well was plotted against time. Linear regression analysis of the initial velocity (slope) of each curve yielded an activity for each sample.

Assessment of cell viability. Cell viability was measured by retention and deesterification of calcein AM (Eldadah et al., 1997). For the calcein AM retention assay, culture media in 96-well plates were replaced with $5 \mu \mathrm{M}$ calcein AM (Molecular Probes, Eugene, OR) in Locke's buffer containing (in mM): $154 \mathrm{NaCl}, 5.6 \mathrm{KCl}, 3.6 \mathrm{NaHCO}_{3}, 2.3 \mathrm{CaCl}_{2}, 1.2 \mathrm{MgCl}_{2}, 5.6$ glucose, and 5 HEPES, pH 7.4. After incubation at $37^{\circ} \mathrm{C}$ for $30 \mathrm{~min}$, fluorescence was measured using a CytoFluor 4000 fluorometer at 485 $\mathrm{nm}$ excitation and $560 \mathrm{~nm}$ emission wavelengths.

Immunoblot analysis. Brain tissue or primary neurons were harvested, washed once with ice-cold PBS, and lysed on ice in a solution containing 50 mm Tris-HCl, pH 7.5, 150 mм NaCl, 1 mм EGTA, 1 mм PMSF, 0.5\% NP-40, $0.25 \%$ SDS, $5 \mu \mathrm{g} / \mathrm{ml}$ leupeptin, and $5 \mu \mathrm{g} / \mathrm{ml}$ aprotinin. After removal of cell debris by centrifugation, the protein concentration of the cell lysate was determined with the Bio-Rad protein assay reagent. A portion of the lysate $(50-80 \mu \mathrm{g}$ of protein) was then fractionated by SDS-PAGE, and the separated proteins were transferred to a nitrocellulose filter. The filter was stained with Ponceau $\mathrm{S}$ to confirm equal loading and transfer of samples and was then probed with specific antibodies. Immune complexes were detected with appropriate secondary antibodies and chemiluminescence reagents (Pierce, Rockford, IL). A polyclonal rabbit antibody to caspase-3 (H-277) was obtained from Santa Cruz Biotechnology (Santa Cruz, CA); a polyclonal rabbit antibody to active caspase-3 (9661) was obtained from Cell Signaling Technology (New England Biolabs, Beverly, MA); a monoclonal mouse antibody to caspase-9 (clone 5B4) was obtained from Medical and Biological Laboratories (MBL); and a polyclonal rabbit antibody to Apaf-1 (AB16941) was obtained from Chemicon.

Reverse transcription-PCR. The levels of mRNA were analyzed using a reverse transcription (RT)-PCR approach as previously described (Yakovlev et al., 1997). In brief, total RNA was isolated by acidic phenol extraction (Chomczynski and Sacchi, 1987), and $10 \mu \mathrm{g}$ of it was reverse transcribed with Moloney murine leukemia virus RT (Life Technologies) in $30 \mu \mathrm{l}$ reaction mixture. The resulting cDNA $(3 \mu \mathrm{l})$ was amplified by PCR. Numbers of cycles and reaction temperature conditions were estimated to be optimal to provide a linear relationship between the amount of input template and the amount of PCR product generated over a wide concentration range: from 1 to $20 \mu \mathrm{g}$ of total RNA, as described in detail previously (Yakovlev and Faden, 1994). Primers to amplify the rat caspase-3 cDNA were 5'-GGTATTGAGACAGACAGTGG-3' (sense primer) and 5'-CATGGGATCTGTTTCTTTGC-3' (antisense primer). Primers to amplify the rat caspase-9 cDNA were 5'-ACAAGGCCTTCGACAGTG-3' (sense primer) and 5'-GTACCAGGAACCGCTCTT-3' (antisense primer). Primers to amplify the rat Apaf- 1 cDNA were 5'-GATATGGAATGTCTCAGATGGCC-3' (sense primer) and 5'GGTCTGTGAGGACTCCCCA-3' (antisense primer). Amplified cDNA was analyzed in agarose electrophoretic gels. After staining with ethidium bromide, UV light gel images were captured and analyzed using the Image 1.59 program. Levels of individual mRNA were expressed in 
A

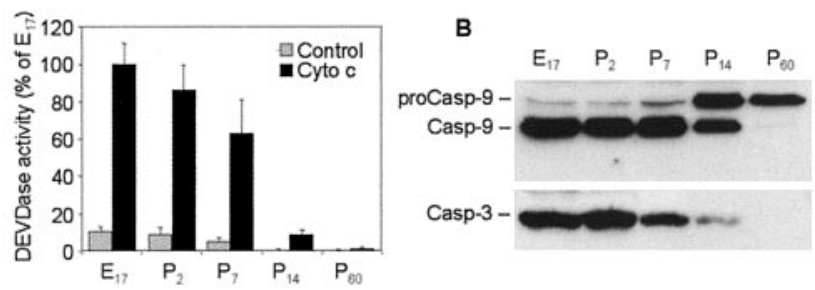

Figure 1. Age-dependent susceptibility of cytosolic protein extracts from rat cortex to cytochrome $c$ - and dATP-dependent activation of caspase-3. $A$, Fifty microgram aliquots of cytosolic protein extracts isolated from cortex of $\mathrm{E} 17$ or $\mathrm{P} 2, \mathrm{P} 7, \mathrm{P} 14$, and $\mathrm{P} 60$ rat brains were incubated in the presence or absence of cytochrome $c$ (Cyto $c$ ) and dATP in caspase activation buffer as described in Materials and Methods. Caspase-3-like activity in treated and control extracts was assayed fluorometrically by measuring the accumulation of free AMC resulting after cleavage of Ac-DEVD-AMC. Protease activity is expressed as percentage of E17 (mean value) $\pm \mathrm{SD}(n=5)$. $B$, Fifty microgram aliquots of cytosolic extracts were treated as described in $A$, subjected to $12 \%$ SDS-PAGE, and transferred to nitrocellulose filters. The filters were probed with a monoclonal anti-caspase-9 (Casp-9) antibody (clone 5B4; MBL) or with a rabbit polyclonal antibody against p17 cleaved form of caspase-3 (Casp-3; Cell Signaling Technology). The antigen-antibody complexes were visualized by an ECL method as described in Materials and Methods. These experiments were repeated in four occasions with similar results.

arbitrary units as the proportion of individual PCR product mean optical density (inverted image) to a control product mean optical density obtained from the same RNA sample. The cDNA for glyceraldehyde-3phosphate dehydrogenase (GAPDH) was used as the internal control, because its levels remain constant in different models tested. Primers to amplify rat GAPDH cDNA were 5'-TAAAGGGCATCCTGGGCTACACT-3' (sense primer) and 5'-TTACTCCTTGGAGGCCATGTAGG-3' (antisense primer). The identity of a PCR-generated product to a corresponding cDNA was confirmed by the sequencing of the PCR products.

Production of recombinant Apaf-1XL. Recombinant human Apaf-1XL was purified essentially as it was described by us earlier (Yakovlev et al., 2000). The full-length coding cDNA clone was kindly provided by Dr. Gabriel Nunez. A pET21c(+) expression vector (Novagen, Madison, WI) containing the coding region for Apaf-1XL was used for the production of the His-tagged protein. The expression plasmid was transformed into a BL21(DE3)pLysS Escherichia coli strain. After induction with $1 \mathrm{~mm}$ isopropyl-1-thio- $\beta$ b-D-galactopyranoside, Apaf-1XL was isolated from bacterial inclusion bodies using Ni-nitrilotriacetic acid agarose (Qiagen, Hilden, Germany) according to the manufacturer's protocol. The yield of recombinant Apaf-1XL was as low as a few micrograms of protein per liter of bacterial culture, probably because of high toxicity of this protein.

Data analysis. Changes in mRNA content, activity for caspase-3, and neuronal viability were analyzed using ANOVA, followed by Dunnett's test; $p<0.05$ was considered statistically significant.

\section{RESULTS}

To assess effectiveness of the cytochrome $c$-dependent caspase- 3 activation pathway in rat brain at different stages of development, we used a well-established assay of reconstitution of cytochrome $c$-dependent caspase-3 activation in vitro. Cytochrome $c$ and dATP are necessary for the oligomerization and binding of Apaf-1 to procaspase- 9 followed by autoactivation of this caspase. Active caspase-9, in turn, cleaves and activates downstream caspases, including caspase-3. Therefore, we incubated cell-free cytosolic extracts isolated from rat brain cortex on embryonic day 17 (E17) or postnatal day 2 (P2), P7, P14, and P60 in the absence or presence of cytochrome $c$ and dATP. As an outcome, we used a fluorogenic substrate assay to measure caspase-3-like (DEVDase) enzyme activity levels in the cortical extracts (Fig. 1A).

High levels of cytochrome $c$-induced DEVDase activity were found in extracts from E17 and P2 rat cortex with no considerable difference between these two age groups. In contrast, activity of DEVDase in P7 protein extracts decreased to $\sim 65 \%$ of embryonic and neonatal levels. DEVDase activity in P14 extracts decreased further, reaching nearly $10 \%$ of E17, and was not detected in extracts from mature (P60) brain. No DEVDase activity was detected also in extracts preincubated in the absence of cytochrome $c$ (Fig. $1 A$ ).

Because cytochrome $c$-dependent activation of caspase- 3 requires activation of caspase-9, we next examined cleavage of these two caspases by Western blot analysis. Using a monoclonal 5B4 anti-caspase-9 antibody (MBL) that recognizes both rat procaspase- 9 and its large subunit, we observed nearly complete cleavage of procaspase-9 in E17, P2, and P7 extracts (Fig. 1B). The degree of caspase- 9 cleavage was markedly decreased in P14 extracts and was not detected in P60 extracts. Using a polyclonal anti-caspase-3 antibody from Cell Signaling Technology that recognizes p17 cleaved fragments, we found that, consistent with results of DEVDase activity assay, caspase-3 was cleaved to its active form in E17, P2, and P7 extracts and to lesser extent in P14 extracts, but such cleavage was not detected in P60 extracts (Fig. $1 B)$. Similar age-dependent changes in cytochrome $c$-dependent apoptotic susceptibility were found in developing mouse brain (data not shown).

To identify a potential molecular basis for the observed agedependent change in cytochrome $c$-dependent apoptotic potential, we examined expression of each component of the apoptosome during rat brain development at mRNA and protein levels. mRNA levels were estimated by RT-PCR analysis. These experiments were based on the available rat Apaf-1, caspase-3, and caspase-9 mRNA sequences (GenBank accession numbers NM023979, U58656, and AF262319, respectively). RT-PCR experiments revealed that Apaf-1 and caspase- 3 mRNA levels decreased markedly in the rat cortex between 1 and 2 weeks after birth and were sustained at these levels in the mature brain (Fig. $2 A$ ). In contrast, caspase-9 mRNA expression was not significantly changed during development.

To examine whether the observed decrease of caspase- 3 and Apaf-1 mRNA correlated with decreased expression of the corresponding proteins, we estimated Apaf-1, procaspase-3, and procaspase- 9 protein expression in rat cortex at the same times in rat brain development. Protein expression was assayed by Western blot analysis. Identification of procaspase- 3 and procaspase- 9 was performed by staining with $\mathrm{H}-277$ and 5B4 antibodies (Santa Cruz Biotechnology and MBL, respectively), which, in each case, recognized a major protein band of a predicted molecular weight. Among a number of anti-Apaf-1 antibodies tested in this study, only a polyclonal rabbit antibody (AB16941; Chemicon) recognized a band of $\sim 140 \mathrm{kDa}$, corresponding to predicted molecular weight of rat Apaf-1 (140 kDa), whereas the rest of tested antibodies stained a $\sim 110 \mathrm{kDa}$ protein of unknown origin. The specificity of this antibody was confirmed in preliminary experiments in which immunostaining of Apaf-1 in rat brain samples was compared with staining of human recombinant Apaf-1 and Apaf-1 preparations purified from bovine thymus (Fig. 3).

As shown in Figure $2 B$, levels of both Apaf-1 and caspase- 3 proteins in cortical extracts were markedly decreased after 1 week of age and were minimal in the mature tissue. In contrast, no significant changes in caspase-9 protein expression were detected in this experiment.

To investigate further age-dependent changes in neuronal susceptibility to apoptosis, we analyzed the level of Apaf-1 protein expression, cytochrome $c$-mediated caspase- 3 activation, and 
A

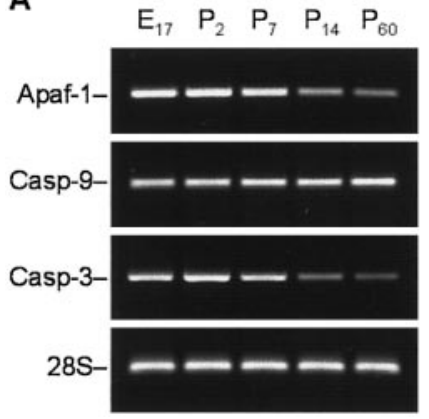

B

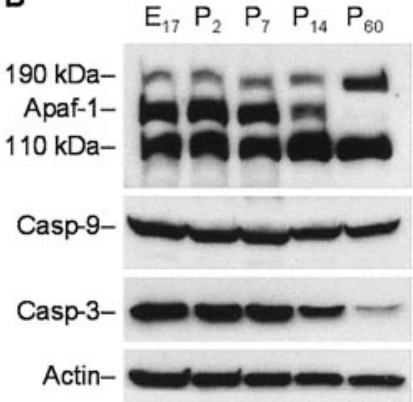

Figure 2. Analysis of age-dependent expression of Apaf-1, caspase-9, and caspase- 3 mRNA and proteins in rat cortex. $A$, RT-PCR analysis of the abundance of transcripts encoding rat Apaf-1, caspase-9 (Casp-9), and caspase-3 (Casp-3) in cortex of E17 or P2, P7, P14, and P60 rat brains. Total RNA from rat cortex on the indicated days of development was subjected to RT-PCR with primers specific for Apaf-1, caspase-9, and caspase-3. Amplification of 28S rRNA was used as an internal control. The PCR products were analyzed by electrophoresis through an agarose gel and visualized after staining with ethidium bromide. $B$, Western blot analysis of the abundance of Apaf- 1 and procaspases- -9 and -3 in the protein extracts isolated from rat cortex on the indicated days of rat development. Eighty microgram aliquots of cytosolic protein extracts isolated from rat brain cortex at indicated developmental stages were subjected to 5\% (Apaf-1) or 12\% SDS-PAGE and transferred to a nitrocellulose filter. The filters were probed with a polyclonal anti-Apaf-1 antibody (AB16941; Chemicon), a monoclonal anti-caspase-9 antibody (clone 5B4; MBL), or a rabbit polyclonal antibody against caspase-3 (H-277, Santa Cruz Biotechnology). The antigen-antibody complexes were visualized by an ECL method as described in Materials and Methods. $\beta$-Actin protein abundance was used as an additional control for gel loading and transfer. These experiments were repeated four times with similar results.

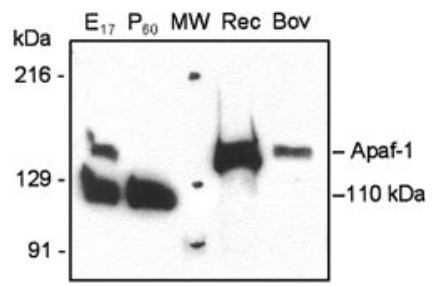

Figure 3. Analysis of anti-Apaf-1 antibody specificity. Fifty micrograms of cytosolic proteins from E17 and P60 rat cortex, $20 \mathrm{ng}$ of recombinant human Apaf-1 (Rec), 10 ng of Apaf-1 purified from bovine thymus (Bov), and $5 \mu \mathrm{l}$ of prestained standards ( $M W$; Bio-Rad, catalog \#161-0324) were separated in 5\% SDS-PAGE followed by staining with a polyclonal antibody (AB16941; Chemicon). The preparation of purified bovine Apaf-1 demonstrated Apaf-1 activity in the in vitro reconstitution system with cytochrome $c$ (data not shown). Results show the location of the Apaf-1 protein band above the extensively stained $110 \mathrm{kDa}$ protein of unknown origin.

etoposide-induced cell death in primary rat cortical neurons cultured for 1, 7, or 14 DIV. Western analysis showed that Apaf-1 expression was clearly decreased in 14 DIV primary neurons compared with 1 DIV cells, a result consistent with Apaf-1 protein expression in developing rat cortex (Fig. 4A). The difference in expression levels of Apaf-1 in 1 and 7 DIV cells was not obvious (data not shown). Incubation of cytosolic extracts from 1 DIV primary neurons in the presence of cytochrome $c$ and dATP led to marked activation of caspase-3; in contrast, activation of caspase-3 in extracts from 7 DIV cells was $\sim 30 \%$ lower and in 14 DIV neurons was approximately fivefold lower that in 1 DIV extracts (Fig. 4B). Similar differences in levels of caspase-3 activity were observed in the cytosol from primary neurons treated
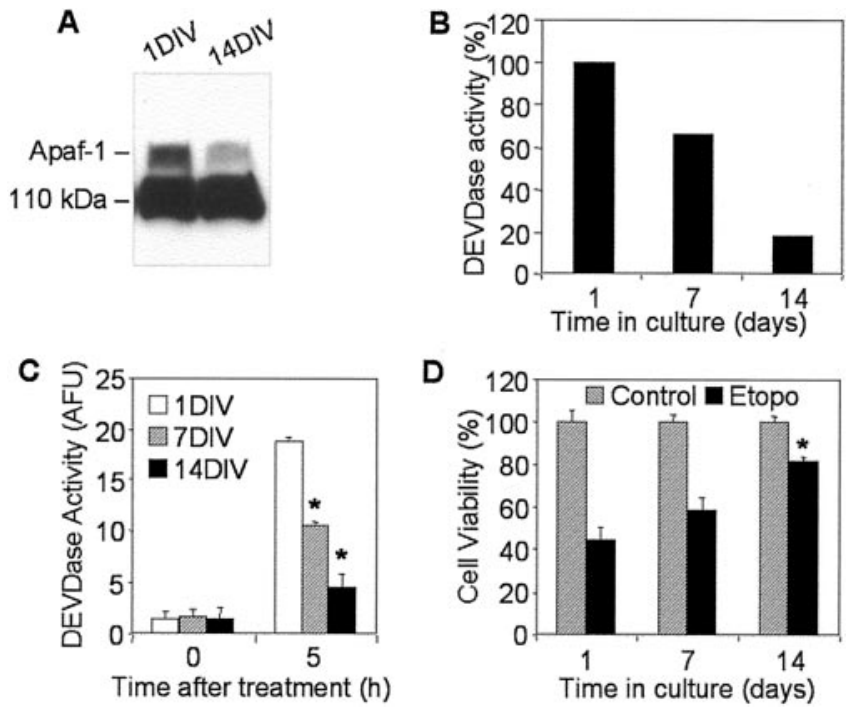

Figure 4. Analyses of Apaf-1 expression, cytochrome $c$-inducible apoptotic potential, and cell viability in primary cultures of rat cortical neurons. $A$, One hundred micrograms of cytosolic proteins from 1 or 14 DIV primary rat cortical neurons were separated in 5\% SDS-PAGE followed by staining with an Apaf-1 antibody (Chemicon). B, Protein extracts from 1,7 , or 14 DIV primary rat cortical neurons were incubated in the presence of cytochrome $c$ and dATP as described in Materials and Methods. Caspase-3-like activity was assayed fluorometrically by measuring the accumulation of free AMC resulting after cleavage of Ac-DEVDAMC. Data are expressed as percentage of 1 DIV-induced caspase activity. $C$, One, 7 , or 14 DIV primary rat cortical neurons were treated with $50 \mu \mathrm{M}$ etoposide for $5 \mathrm{hr}$. Control cultures $(0 \mathrm{hr})$ served as negative controls. Caspase-3-like activity in cytosolic extracts from treated or control cells was assayed fluorometrically. Protease activity is expressed in arbitrary fluorescence units $\pm \mathrm{SD}(n=6)$. $* p<0.001$, compared with caspase-3 activity in etoposide-treated 1DIV cells, by ANOVA, followed by Dunnett's test. $D$, One, 7 , or 14 DIV primary neurons were treated with $50 \mu \mathrm{M}$ etoposide (Etopo) for $24 \mathrm{hr}$, and cell viability was analyzed by measurement of calcein AM fluorescence. Data are expressed as a percentage of the value for control cells not exposed to etoposide $\pm \mathrm{SD}(n=$ $6)$. ${ }^{*} p<0.001$, compared with viability of 1DIV cells after $24 \mathrm{hr}$ etoposide treatment, by ANOVA, followed by Dunnett's test.

with etoposide: $5 \mathrm{hr}$ treatment of 1 DIV cells resulted in activity of caspase- 3 corresponding to $18.7 \pm 0.4$ arbitrary units of fluorescence (AUF); in contrast, activity in 14 DIV extracts was only $4.7 \pm 0.1$ AUF (Fig. 4C). Changes in caspase-3 activity in the etoposide-treated neurons correlated inversely with the degree of cell survival. After $24 \mathrm{hr}$ incubation of $1 \mathrm{DIV}$ neurons with etoposide, $45 \pm 6 \%$ of cells survived, whereas in 7 DIV cultures, $55 \pm 5 \%$ of cells survived, and in 14 DIV cultures, $79 \pm 3 \%$ of cells were viable (Fig. 4D).

Our previous report suggested that brain trauma in rats results in activation of caspase-3 (Yakovlev et al., 1997). Because activation of caspase-3 results from specific cleavage of the precursor protein, we examined such cleavage of caspase- 3 using Western analysis as a function of time after TBI. Consistent with previous findings, low levels of the cleaved forms of caspase- 3 were detected beginning $4 \mathrm{hr}$ after trauma but increased markedly at 48 hr after injury (Fig. 5).

Because the apoptotic potential in mature brain tissue is repressed, and such repression may be predetermined by downregulation of both Apaf-1 and caspase-3 gene expression, we hypothesized that elevation of caspase- 3 activity after TBI may require reactivation of these genes in the mature brain. In part, this hypothesis is supported by results of our previous studies in which 


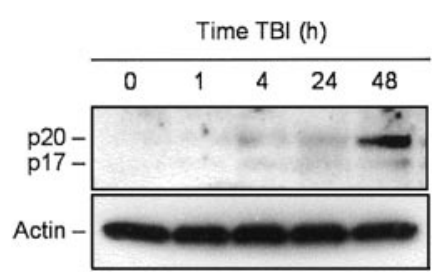

Figure 5. TBI-induced specific cleavage of procaspase-3 in rat brain cortex. Eighty microgram aliquots of cytosolic protein extracts isolated from sham control or traumatized rat cortex at indicated times after TBI were subjected to $12 \%$ SDS-PAGE and transferred to a nitrocellulose filter. The filter was probed with a rabbit polyclonal antibody against a p17 cleaved form of procaspase-3 (Cell Signaling Technology). To control protein loading, membranes were stripped and reprobed with an antibody against $\beta$-actin. A significant increase in caspase-3 cleavage was observed $48 \mathrm{hr}$ after injury.
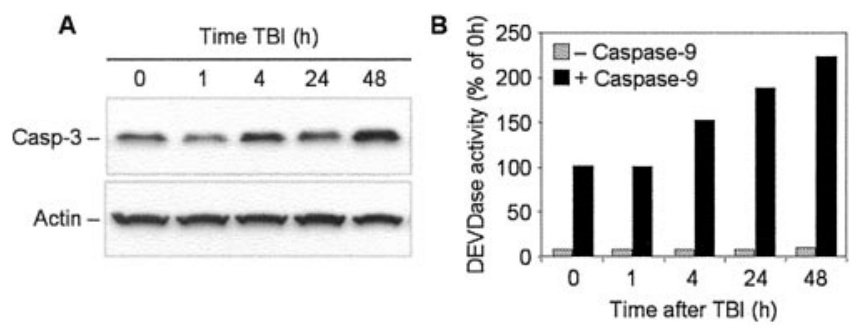

Figure 6. Time course of procaspase-3 protein expression in rat brain cortex after TBI. $A$, Fifty microgram aliquots of cytosolic protein extracts isolated from sham control or traumatized rat cortex at indicated times after TBI were subjected to $12 \%$ SDS-PAGE and transferred to a nitrocellulose filter. The filter was probed with a rabbit polyclonal antibody against caspase-3 (Casp-3; H-277; Santa Cruz Biotechnology). The antigen-antibody complexes were visualized by an ECL method as described in Materials and Methods. To control protein loading, membranes were stripped and reprobed with an antibody against $\beta$-actin. $B$, Fifty microgram aliquots of cytosolic protein extracts isolated from sham control or traumatized rat cortex at indicated times after TBI were incubated with or without active recombinant human caspase-9 (20 U; Biomol, Plymouth Meeting, PA) in $50 \mu \mathrm{l}$ of caspase activation buffer at $37^{\circ} \mathrm{C}$ for $1 \mathrm{hr}$. Caspase-3-like activity was assayed fluorometrically by measuring the accumulation of free AMC. Protease activity is expressed as a percentage of the activity in sham-operated control extracts.

we found that TBI results in an early increase in caspase- 3 mRNA content in the injured brain regions (Yakovlev et al., 1997). In this study, we examined protein expression of procaspase- 3 in injured cortex as a function of time after brain trauma. Using Western blot analysis, we found that procaspase-3 protein levels were elevated in injured cortex by $4-48 \mathrm{hr}$ after TBI (Fig. 6 $A$ ).

Because of the limitations of Western blot for quantitative analysis of protein expression, we examined whether the apparent increase in procaspase- 3 after TBI leads to an increase in corresponding caspase activity after experimental cleavage by active recombinant caspase-9. As shown in Figure 6B, TBI induced a significant elevation of caspase-9-mediated caspase-3 activity in extracts from injured cortex. A 1.5-fold increase in caspase-9dependent caspase- 3 activation was observed in extracts isolated from injured cortex $4 \mathrm{hr}$ after TBI. This induced activity was further increased at later time points after TBI, exceeding twice control levels by $2 \mathrm{~d}$ after injury. No such changes in caspase- 3 activity were detected in contralateral brain regions (data not shown).

Injury-induced increases in caspase- 3 protein expression observed in this study are consistent with increases in activity of this caspase after TBI. On the other hand, activation of caspase- 3

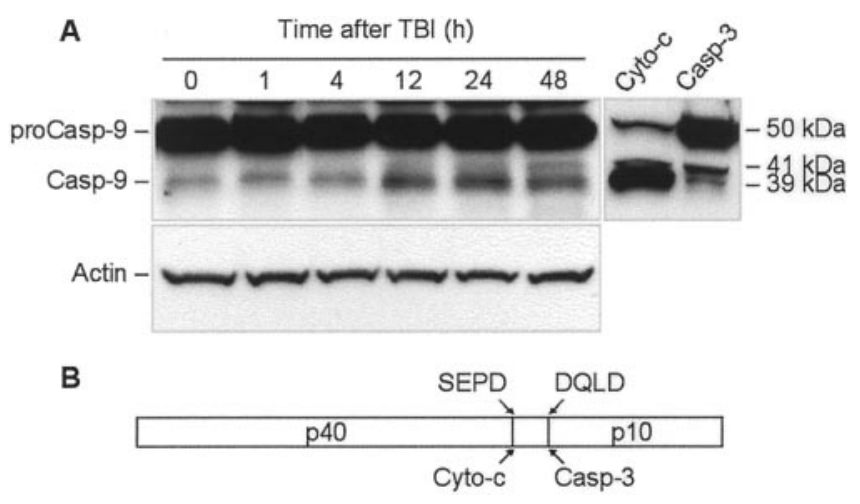

Figure 7. TBI induces time-dependent cleavage of procaspase-9 in rat brain cortex. $A$, Eighty microgram aliquots of cytosolic protein extracts isolated from sham control or traumatized rat cortex at indicated times after TBI were subjected to $10 \%$ SDS-PAGE and transferred to a nitrocellulose filter. As a positive control for cleavage specificity, $80 \mu \mathrm{g}$ aliquots of protein extracts from 2-d-old rat cortex were preincubated in the presence of either recombinant active rat caspase-3 (Casp-3; $20 \mathrm{U}$; Alexis) or cytochrome $c($ Cyto- $c)$ and dATP for $1 \mathrm{hr}$ at $37^{\circ} \mathrm{C}$. The filter was probed with a monoclonal antibody against caspase-9 (Casp-9; clone 5B4; MBL). The antigen-antibody complexes were visualized by an ECL method as described in Materials and Methods. To control protein loading, membranes were stripped and reprobed with an antibody against $\beta$-actin. $B$, Schematic diagram illustrating processing of procaspase-9. Procaspase- 9 is processed preferentially at the SEPD site within the apoptosome and at the DQLD site by caspase-3 to generate the large subunit ( $p 40)$ and small subunit $(p 10)$ of mature caspase-9.

requires previous activation of caspase- 9 within the apoptosome. We found that in the mature brain this pathway is repressed, in part, because of downregulation of Apaf-1 expression. Therefore, we hypothesized that neuronal injury may lead to reactivation of the intrinsic pathway of apoptosis via reactivation of Apaf-1 gene expression. To test this hypothesis at the functional level, we first examined whether specific cleavage of caspase- 9 could be detected after TBI. This was assessed by Western analysis of cortical protein extracts in the time course after trauma.

Amino acid sequence analysis of rat procaspase-9 revealed that, like human procaspase-9, it contains an SEPD potential autoactivation cleavage site and a DQLD caspase-3 recognition site. Correspondingly, cytochrome $c$-mediated autoactivation is expected to produce a $39 \mathrm{kDa}$ large subunit recognizable by the antibodies, whereas, a $41 \mathrm{kDa}$ large fragment is expected after cleavage with caspase-3 (Fig. 7). Indeed, treatment of P2 cortical extracts with cytochrome $c$ and dATP resulted in cleavage of caspase-9 corresponding to the $39 \mathrm{kDa}$ subunit, whereas treatment of the extracts with recombinant active rat caspase-3 (Alexis) primarily resulted in appearance of the $41 \mathrm{kDa}$ fragment. Notably, processing of procaspase- 9 by caspase- 3 was less efficient compared with that by cytochrome $c$ treatment (Fig. 7).

Western blot analysis of protein samples of injured cortex showed accumulation of the $39 \mathrm{kDa}$ caspase- 9 subunit after TBI. At $48 \mathrm{hr}$ after injury, the $41 \mathrm{kDa}$ caspase- 9 fragment also became apparent, reflecting increased caspase- 3 activity in the samples at this time point (Fig. 7).

Injury-induced cleavage of procaspase- 9 at autoactivationspecific sites presumes that injury reactivates the apoptosome complex, which, as we show here, is normally repressed in the mature brain. Therefore, we next examined whether expression of Apaf-1 mRNA and protein are affected by TBI.

Results of semiquantitative RT-PCR showed that Apaf-1 mRNA content increased in the injured cortex, reaching $143 \pm$ 

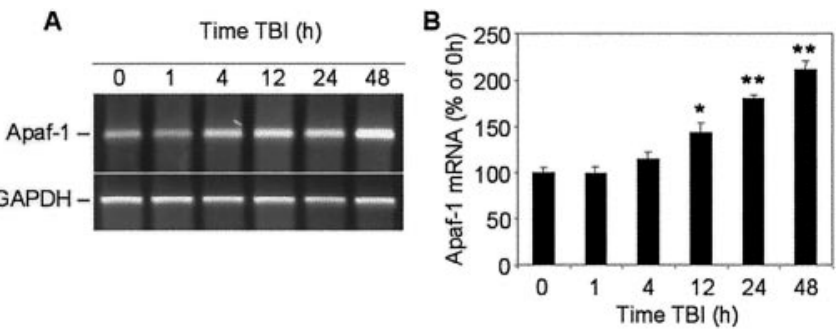

Figure 8. Time course of Apaf-1 mRNA expression in rat cortex at indicated times after TBI or in sham-operated controls $(0 \mathrm{hr})$. A, Levels of mRNA were measured by using semiquantitative RT-PCR as indicated in Materials and Methods. $B$, Levels of Apaf- 1 mRNA are expressed as the proportion of individual RT-PCR product mean optical density to GAPDH RT-PCR product optical density of the same RNA sample. mRNA content is expressed as a percentage of sham controls \pm SEM $(n=5) .{ }^{*} p<0.05$; ${ }^{*} p<0.005$, compared with control, by ANOVA, followed by Dunnett's test.

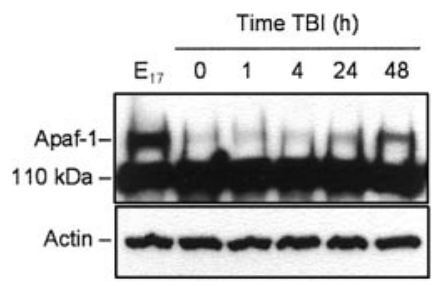

Figure 9. TBI induces a time-dependent increase in Apaf-1 protein content in rat brain cortex. Eighty microgram aliquots of cytosolic protein extracts isolated from rat brain cortex at E17 or from sham control $(0 \mathrm{hr})$ or traumatized rat cortex at indicated times after TBI were subjected to 5\% SDS-PAGE and transferred to a nitrocellulose filter. The filter was probed with a rabbit polyclonal antibody against human Apaf-1 (AB16941; Chemicon). To control protein loading, the same samples were subjected to $10 \%$ SDS-PAGE, transferred to a nitrocellulose filter, and probed with an antibody against $\beta$-actin. The antigen-antibody complexes were visualized by an ECL method as described in Materials and Methods. This experiment was repeated three times with similar results.

$10 \%$ of control (sham) levels by $12 \mathrm{hr}, 180 \pm 5 \%$ by $24 \mathrm{hr}$, and $211 \pm 9 \%$ by $48 \mathrm{hr}$ after TBI (Fig. $8 A, B$ ). Furthermore, Western blot revealed increased intensity of the Apaf-1 protein band in cortical extracts isolated $24 \mathrm{hr}$ after injury, with a peak expression at $48 \mathrm{hr}$ (Fig. 9).

\section{DISCUSSION}

Activation of caspase-3 appears to be a critical event in the execution of neuronal apoptosis in the brain during development and after acute injury (Kuida et al., 1996; Bredesen, 2000; Eldadah and Faden, 2000). In the intrinsic pathway of caspase-3 activation, Apaf-1, caspase-9, and cytochrome $c$ work together forming the apoptosome complex (Li et al., 1997; Z ou et al., 1997, 1999), which, in the presence of dATP, leads to activation of caspase-9 ( $\mathrm{Li}$ et al., 1997). Active caspase-9, in turn, activates caspase-3.

A role for the apoptosome-mediated pathway of neuronal apoptosis in brain development has been established through transgenic studies (Cecconi et al., 1998; Hakem et al., 1998; Yoshida et al., 1998; Honarpour et al., 2000). Recently, a functional role for this pathway in injury-induced neuronal apoptosis also was demonstrated in models of brain (Krajewski et al., 1999) and spinal cord injury (Springer et al., 1999). This suggests that the same pathway may be functional in physiological apoptosis during brain development and in pathological processes related to CNS injury.

In the present study, we examined the intrinsic pathway of caspase- 3 activation in rat brain cortex and in primary rat cortical neurons as a function of developmental age and as a function of time after traumatic injury to mature brain. We also investigated expression of Apaf-1, caspase-9, and caspase-3 genes at mRNA and protein levels, given the role of these proteins in developmental and injury-induced neuronal apoptosis.

Using an in vitro system, we demonstrated that the ability of cytochrome $c$ to induce activation of caspase-3 was decreased during maturation of rat brain and was undetectable by the caspase activity assay and by Western blot in rat (and mouse; data not shown) brain samples after 2 weeks of age. This observation is consistent with recent reports on age-dependent differences in injury-induced caspase-3 activation and susceptibility to apoptosis in mammalian brain (Bittigau et al., 1999; Pohl et al., 1999; Hu et al., 2000).

Results of Western blot experiments showed that agedependent declines in cytochrome $c$-dependent activation of caspase- 3 in rat brain cortex paralleled the extent of procaspase- 9 processing in the in vitro assay. This suggests that repression of cytochrome $c$-dependent apoptotic potential might be regulated at the level of the apoptosome. To address this issue, we analyzed Apaf-1, caspase-9, and caspase-3 gene expression as a function of developmental age.

We found that mRNA and protein expression for both Apaf-1 and caspase- 3 were markedly decreased in rat cortex during brain development. The age-dependent decrease in caspase-3 mRNA content in rat brain tissue is consistent with previously published data (Zou et al., 1997; de Bilbao et al., 1999). Profiles of both Apaf- 1 and caspase- 3 gene expression were comparable with the developmental profile of cytochrome $c$-mediated caspase- 3 activation in rat brain. Interestingly, caspase- 9 gene activity, at both mRNA and protein levels, did not change notably during brain development, suggesting that activation of this caspase in the brain may depend on the Apaf-1-mediated pathway. Developmental downregulation of caspase- 3 gene activity may serve as a supplementary mechanism that protects the mature brain from apoptosis initiated by other caspases, such as caspase-8, -11, or -12 (Ivins et al., 1999; Raoul et al., 1999; Sanchez et al., 1999; Matsushita et al., 2000; Nakagawa et al., 2000).

Because of the poor specificity of the available anti-Apaf-1 antibodies, we were not able to examine directly whether downregulation of Apaf-1 during brain maturations occurs in neurons. Therefore, we examined Apaf-1 protein expression, cytochrome $c$-dependent activation of caspase-3, and etoposide-induced apoptosis in primary rat cortical neurons cultured for 1 or 14 DIV. Both Apaf-1 expression and apoptosome-mediated activation of caspase-3 were markedly decreased in 14 DIV neurons. Decreased levels of caspase-3 activity and highly significant reduction of associated apoptosis were also found in neurons at 14 DIV (vs 1 DIV) treated with etoposide. In transfection studies using dominant negative mutant constructs of caspase- 8 and -9 , we have demonstrated that etoposide-induced apoptosis in rat primary cortical neurons, as well as in the SH-SY5Y neuroblastoma cell line, proceeds through a caspase-9-dependent pathway (data not shown). Collectively these data support the hypothesis that neuronal maturation in vitro leads to repression of cytochrome $c$-dependent apoptotic susceptibility and that this process parallels the decrease in Apaf-1 protein expression in rat cortical neurons. 
Given the present findings and previous observations that brain injury causes activation of caspase-3 and related neuronal apoptosis, we examined whether TBI recapitulates apoptotic potential via coordinated reactivation of caspase- 3 and Apaf-1 genes. Increased caspase-3 mRNA levels after neuronal injury have been demonstrated previously in various models of apoptosis, including TBI (Yakovlev et al., 1997; Clark et al., 2000); however, changes in procaspase-3 protein levels have not been reported. Therefore, we examined expression of procaspase- 3 protein as a function of time after brain trauma, using Western analysis and by measuring caspase-9-induced caspase-3 activity in extracts from injured cortex. Both techniques showed a marked increase in procaspase-3 after TBI.

Preliminary analysis of caspase- 8 cleavage and activation in cortical protein extracts after brain injury did not suggest a role for caspase- 8 in TBI-induced cell death (data not shown). In contrast, brain trauma resulted in accumulation of cleavage fragments of caspase- 9 in rat cortex after injury that paralleled activation-specific cleavage of caspase-3.

Given the repression of Apaf-1 in normal mature brain cortex, we examined whether its levels were increased after brain injury. RT-PCR and Western blot showed that Apaf-1 mRNA and protein content were substantially increased after fluid percussioninduced TBI compared with sham-injured controls.

A role for Apaf-1 gene regulation in apoptosis has been suggested recently by in vitro studies. Robles et al. (1999) demonstrated that downregulation of Apaf-1 protein expression in granulosa cells by treatment with gonadotropin completely suppressed apoptotic cell death via the intrinsic procaspase-3 processing pathway. Soengas et al. (2001) reported that metastatic melanomas often lose Apaf-1 expression. Moreover, Apaf-1-negative cells are consistently chemoresistant and are unable to undergo apoptosis in response to p53 activation. The authors showed that loss of Apaf-1 expression can be recovered by treatment with the methylation inhibitor 5-aza-2'-deoxycytidine. Restoring physiological levels of Apaf-1 rescued the apoptotic defects associated with Apaf-1 loss. These authors suggested that inactivation of the Apaf-1 gene may result from methylation of an enhancer or other regulatory elements outside the Apaf-1 core promoter (Soengas et al., 2001). We do not exclude that methylation may also contribute to downregulation of Apaf-1 during brain development.

In addition, Moroni et al. (2001) recently reported that the expression of Apaf-1 gene can be directly regulated by E2F1 transcription factor and that Apaf- 1 is a direct transcriptional target of the tumor suppressor p53. The previous studies demonstrated that p53 is upregulated in vulnerable cells in response to lateral fluid percussion brain injury in the rat (Napieralski et al., 1999). These observations suggest that injury-induced p53 expression might sensitize cells to apoptosis by increasing Apaf-1 levels.

Taken together, our findings are consistent with previous observations on differential susceptibility to apoptosis and associated caspase-3 activity in developing and mature brain tissues (Bittigau et al., 1999; Pohl et al., 1999; Hu et al., 2000). In addition, this report suggests a potential molecular mechanism underlying such age-dependent differences and indicates that Apaf- 1 and caspase-3 gene expression is normally repressed in the adult brain. Acute brain injury appears to recapitulate earlier expression patterns for these proapoptotic genes that lead to apoptosis. Development of specific antibodies and inhibitors of Apaf-1 will help clarify the role of this protein in developmental neuronal apoptosis as well as in injury-induced apoptotic cell death.

\section{REFERENCES}

Adelson PD, Kochanek PM (1998) Head injury in children. J Child Neurol 13:2-15.

Beattie MS, Farooqui AA, Bresnahan JC (2000) Review of current evidence for apoptosis after spinal cord injury. J Neurotrauma 17:915-925.

Bittigau P, Sifringer M, Pohl D, Stadthaus D, Ishimaru M, Shimizu H, Ikeda M, Lang D, Speer A, Olney JW, Ikonomidou C (1999) Apoptotic neurodegeneration following trauma is markedly enhanced in the immature brain. Ann Neurol 45:724-735.

Bredesen DE (2000) Apoptosis: overview and signal transduction pathways. J Neurotrauma 17:801-810.

Brink JD, Garrett AL, Hale WR, Nickel VL, Woo-Sam J (1970) Recovery of motor and intellectual function in children sustaining severe head injuries. Dev Med Child Neurol 12:565-571.

Brown GC, Borutaite V (1999) Nitric oxide, cytochrome $c$ and mitochondria. Biochem Soc Symp 66:17-25.

Cecconi F, Alvarez-Bolado G, Meyer BI, Roth KA, Gruss P (1998) Apaf1 (CED-4 homolog) regulates programmed cell death in mammalian development. Cell 94:727-737.

Chomczynski P, Sacchi N (1987) Single-step method of RNA isolation by acid guanidinium thiocyanate-phenol-chloroform extraction. Anal Biochem 162:156-159.

Clark RS, Kochanek PM, Watkins SC, Chen M, Dixon CE, Seidberg NA, Melick J, Loeffert JE, Nathaniel PD, Jin KL, Graham SH (2000) Caspase-3 mediated neuronal death after traumatic brain injury in rats. J Neurochem 74:740-753.

de Bilbao F, Guarin E, Nef P, Vallet P, Giannakopoulos P, DuboisDauphin M (1999) Postnatal distribution of cpp32/caspase 3 mRNA in the mouse central nervous system: an in situ hybridization study. J Comp Neurol 409:339-357.

Eldadah BA, Faden AI (2000) Caspase pathways, neuronal apoptosis, and CNS injury. J Neurotrauma 17:811-829.

Eldadah BA, Yakovlev AG, Faden AI (1997) The role of CED-3-related cysteine proteases in apoptosis of cerebellar granule cells. J Neurosci 17:6105-6113.

Faden AI, Demediuk P, Panter SS, Vink R (1989) The role of excitatory amino acids and NMDA receptors in traumatic brain injury. Science $244: 798-800$

Gillardon F, Bottiger B, Schmitz B, Zimmermann M, Hossmann KA (1997) Activation of CPP-32 protease in hippocampal neurons following ischemia and epilepsy. Brain Res Mol Brain Res 50:16-22.

Hakem R, Hakem A, Duncan GS, Henderson JT, Woo M, Soengas MS, Elia A, de la Pompa JL, Kagi D, Khoo W, Potter J, Yoshida R, Kaufman SA, Lowe SW, Penninger JM, Mak TW (1998) Differential requirement for caspase 9 in apoptotic pathways in vivo. Cell 94:339-352.

Haydar TF, Kuan CY, Flavell RA, Rakic P (1999) The role of cell death in regulating the size and shape of the mammalian forebrain. Cereb Cortex 9:621-626.

Honarpour N, Du C, Richardson JA, Hammer RE, Wang X, Herz J (2000) Adult Apaf-1-deficient mice exhibit male infertility. Dev Biol 218:248-258.

Hu BR, Liu CL, Ouyang Y, Blomgren K, Siesjo BK (2000) Involvement of caspase-3 in cell death after hypoxia-ischemia declines during brain maturation. J Cereb Blood Flow Metab 20:1294-1300.

Ivins KJ, Thornton PL, Rohn TT, Cotman CW (1999) Neuronal apoptosis induced by beta-amyloid is mediated by caspase- 8 . Neurobiol Dis 6:440-449.

Krajewski S, Krajewska M, Ellerby LM, Welsh K, Xie Z, Deveraux QL, Salvesen GS, Bredesen DE, Rosenthal RE, Fiskum G, Reed JC (1999) Release of caspase-9 from mitochondria during neuronal apoptosis and cerebral ischemia. Proc Natl Acad Sci USA 96:5752-5757.

Kuida K (2000) Caspase-9. Int J Biochem Cell Biol 32:121-124.

Kuida K, Zheng TS, Na S, Kuan C, Yang D, Karasuyama H, Rakic P, Flavell RA (1996) Decreased apoptosis in the brain and premature lethality in CPP32-deficient mice. Nature 384:368-372.

Kulms D, Schwarz T (2000) Molecular mechanisms of UV-induced apoptosis. Photodermatol Photoimmunol Photomed 16:195-201.

Levin HS, Eisenberg HM, Wigg NR, Kobayashi K (1982) Memory and intellectual ability after head injury in children and adolescents. Neurosurgery 11:668-673.

Li P, Nijhawan D, Budihardjo I, Srinivasula SM, Ahmad M, Alnemri ES, Wang X (1997) Cytochrome $c$ and dATP-dependent formation of Apaf-1/caspase-9 complex initiates an apoptotic protease cascade. Cell 91:479-489.

Lipton P (1999) Ischemic cell death in brain neurons. Physiol Rev 79:1431-1568.

Matsushita K, Wu Y, Qiu J, Lang-Lazdunski L, Hirt L, Waeber C, Hyman BT, Yuan J, Moskowitz MA (2000) Fas receptor and neuronal cell death after spinal cord ischemia. J Neurosci 20:6879-6887. 
McIntosh TK, Noble L, Andrews B, Faden AI (1987) Traumatic brain injury in the rat: characterization of a midline fluid-percussion model. Cent Nerv Syst Trauma 4:119-134.

Moroni MC, Hickman ES, Denchi EL, Caprara G, Colli E, Cecconi F, Muller H, Helin K (2001) Apaf-1 is a transcriptional target for E2F and p53. Nat Cell Biol 3:552-558.

Nakagawa T, Zhu H, Morishima N, Li E, Xu J, Yankner BA, Yuan J (2000) Caspase-12 mediates endoplasmic-reticulum-specific apoptosis and cytotoxicity by amyloid-beta. Nature 403:98-103.

Napieralski JA, Raghupathi R, McIntosh TK (1999) The tumorsuppressor gene, p53, is induced in injured brain regions following experimental traumatic brain injury. Brain Res Mol Brain Res 71:78-86.

Pohl D, Bittigau P, Ishimaru MJ, Stadthaus D, Hubner C, Olney JW, Turski L, Ikonomidou C (1999) N-Methyl-D-aspartate antagonists and apoptotic cell death triggered by head trauma in developing rat brain. Proc Natl Acad Sci USA 96:2508-2513.

Raghupathi R, Graham DI, McIntosh TK (2000) Apoptosis after traumatic brain injury. J Neurotrauma 17:927-938.

Raoul C, Henderson CE, Pettmann B (1999) Programmed cell death of embryonic motoneurons triggered through the Fas death receptor. J Cell Biol 147:1049-1062.

Richter C, Ghafourifar P (1999) Ceramide induces cytochrome $c$ release from isolated mitochondria. Biochem Soc Symp 66:27-31.

Robertson JD, Orrenius S (2000) Molecular mechanisms of apoptosis induced by cytotoxic chemicals. Crit Rev Toxicol 30:609-627.

Robles R, Tao XJ, Trbovich AM, Maravel DV, Nahum R, Perez GI, Tilly KI, Tilly JL (1999) Localization, regulation and possible consequences of apoptotic protease-activating factor-1 (Apaf-1) expression in granulosa cells of the mouse ovary. Endocrinology 140:2641-2644.

Sanchez I, Xu CJ, Juo P, Kakizaka A, Blenis J, Yuan J (1999) Caspase-8 is required for cell death induced by expanded polyglutamine repeats. Neuron 22:623-633.

Scaffidi C, Fulda S, Srinivasan A, Friesen C, Li F, Tomaselli KJ, Debatin KM, Krammer PH, Peter ME (1998) Two CD95 (APO-1/Fas) signaling pathways. EMBO J 17:1675-1687.
Slee EA, Harte MT, Kluck RM, Wolf BB, Casiano CA, Newmeyer DD, Wang HG, Reed JC, Nicholson DW, Alnemri ES, Green DR, Martin SJ (1999) Ordering the cytochrome $c$-initiated caspase cascade: hierarchical activation of caspases- $2,-3,-6,-7,-8$, and -10 in a caspase-9dependent manner. J Cell Biol 144:281-292.

Snider BJ, Gottron FJ, Choi DW (1999) Apoptosis and necrosis in cerebrovascular disease. Ann NY Acad Sci 893:243-253.

Soengas MS, Capodieci P, Polsky D, Mora J, Esteller M, Opitz-Araya X McCombie R, Herman JG, Gerald WL, Lazebnik YA, Cordon-Cardo C, Lowe SW (2001) Inactivation of the apoptosis effector Apaf-1 in malignant melanoma. Nature 409:207-211.

Springer JE, Azbill RD, Knapp PE (1999) Activation of the caspase-3 apoptotic cascade in traumatic spinal cord injury. Nat Med 5:943-946.

Yakovlev AG, Faden AI (1994) Sequential expression of c-fos protooncogene, TNF-alpha, and dynorphin genes in spinal cord following experimental traumatic injury. Mol Chem Neuropathol 23:179-190.

Yakovlev AG, Knoblach SM, Fan L, Fox GB, Goodnight R, Faden AI (1997) Activation of CPP32-like caspases contributes to neuronal apoptosis and neurological dysfunction after traumatic brain injury. J Neurosci 17:7415-7424.

Yakovlev AG, Wang G, Stoica BA, Boulares HA, Spoonde AY, Yoshihara $\mathrm{K}$, Smulson ME (2000) A role of the $\mathrm{Ca}^{2+} / \mathrm{Mg}^{2+}$-dependent endonuclease in apoptosis and its inhibition by poly(ADP-ribose) polymerase. J Biol Chem 275:21302-21308.

Yamashima T (2000) Implication of cysteine proteases calpain, cathepsin and caspase in ischemic neuronal death of primates. Prog Neurobiol 62:273-295.

Yoshida H, Kong YY, Yoshida R, Elia AJ, Hakem A, Hakem R, Penninger JM, Mak TW (1998) Apaf1 is required for mitochondrial pathways of apoptosis and brain development. Cell 94:739-750.

Zou H, Henzel WJ, Liu X, Lutschg A, Wang X (1997) Apaf-1, a human protein homologous to $C$. elegans CED-4, participates in cytochrome c-dependent activation of caspase-3. Cell 90:405-413.

Zou H, Li Y, Liu X, Wang X (1999) An APAF-1.cytochrome $c$ multimeric complex is a functional apoptosome that activates procaspase- 9 . J Biol Chem 274:11549-11556. 